\title{
MITOS KECANTIKAN TUBUH WANITA PADA KAKAWIN SMARA TANTRA
}

\author{
Putu Eka Sura Adnyana ${ }^{1}$, Ni Made Yuliarmini ${ }^{2}$ \\ DPP Peradah Indonesia Bali, Universitas Hindu Negeri I Gusti Bagus Sugriwa \\ Denpasar
}

\begin{abstract}
The concept of beauty attached to a woman's body does not only occur in the real world but also in literary works. Beauty myths form interpretations to women in the analyzed Smara Tantra kakawin. Beauty myths intimidate women in such a systematic and organized way. As long as women think that being beautiful according to the representation of society's glasses is an absolute necessity. Kakawin Smara Tantra, which is quite famous among Balinese people, only sees from the point of view of men the beautiful construction of women. Beauty myths created in kakawin Smara Tantra have shackled women so that women no longer respect themselves and only focus on physical form. Although the true beauty of women is not only radiated from the physical but must be balanced with beauty that comes from within (inner beauty).
\end{abstract}

Keywords

Beauty Myth, Women's Body, Kakawin Smara Tantra

\section{PENDAHULUAN}

Pesona kecantikan tubuh wanita memiliki daya estetik dan keluhuran yang sangat agung. Picard (2006:40) menyatakan Balinese women are beautiful as beautiful as one can imagine, with a physiologically simple and dignified beauty, full of Eastern nobility and natural chastity "Wanita Bali sangat cantik, secantik yang dapat kita bayangkan; kecantikan itu anggun dan sederhana secara fisiologis, penuh kemuliaan dari Timur dan kesucian alami".
Pernyataan Pichard tersebut memberikan gambaran bahwasanya wanita dengan pesona kecantikan tubuhnya selalu dijadikan objek dalam aktivitas sosial masyarakat. Kasus historisnya adalah cultural capital berupa keunikan, keagungan dan kemuliaan masa lalu kebudayaan Bali yang dijadikan sebagai media promosi oleh Pemerintah kolonial Belanda. Para wanita yang bertelanjang dada sering dijadikan sasaran pemotretan oleh wisatawan asing yang berkunjung ke Bali. Promosi ini dilakukan

\footnotetext{
1 ekasuraadnyana@gmail.com

2 nimadeyuliarmini1996@gmail.com
} 
melalui lukisan kanfas dan foto-foto wanita Bali yang bertelanjang dada dengan menggunakan ikon "the island of thousand temples" dan "the Last Paradise". Tubuh wanita dijadikan komoditas politik dan kebudayaan sebagai bentuk pelemahan terhadap identitas wanita. Tubuh wanita dianggap sebagai sesuatu yang berbahaya dan perlu dikendalikan melalui kebijakan terhadap tubuh (Susilo \& Kodir, 2016:317).

Keindahan tubuh wanita tersebut tersurat dalam manuscript kuno, salah satunya adalah lontar kakawin Smara Tantra. Membaca awal teks tersebut dijelaskan "Awighnamastu. Sang sampun krta tattwa ning wisaya suddha tumĕmutĕmu sandhi ning smara, ngkaneng Madhya ikang tilam ri huwus ing ulaha nekan i samprayojana, kāma děha sinamādhi sakāla saha yoga dhāraka,siddha mangguhaken rasa mrětta wisesa panggilanga wikalpa karana.. (Orang yang sempurna dalam ajaran bercinta nampak suci telah menemukan rahasia dalam bercinta, selesai atas melakukan hubungan dan memperoleh kenikmatan di ranjang,pengetahuan akan asmara memusatkan pikiran pada ketabahan atas penderitaan, berhasil mencapai kepuasan yang tak terhingga yang mampu memusnahkan penyebab kesengsaraan..).

Teks kakawin Smara Tantra
menyatakan kecantikan merupakan bagian dari kodrat yang harus disandang oleh kaum wanita. Realitas tersebut menyiratkan tentang suatu hal bahwa kecantikan adalah bagian integral dari diri wanita. Budaya yang memberikan kebebasan kepada laki-laki menjadi penentu segalanya, termasuk konsep cantik itu sendiri (Wolf, 2004:23). Hal demikian pada gilirannya juga berdampak pada persepsi wanita itu sendiri yang mengidentifikasi sosok wanita cantik dan ideal sebagai dia yang kurus, tinggi, putih, dan berambut pirang, dengan wajah yang mulus tanpa noda, simetris, hidung mancung, bibir tipis, dada yang menonjol, pinggul yang padat berisi, kaki yang jenjang, dan tanpa cacat sedikit pun. (Wolf, 2004: 4).

Penentuan standar kecantikan dalam suatu masyarakat telah menyebabkan penderitaan bagi sebagian wanita yang dianggap berada di bawah garis kecantikan (Wolf, 2004: 24). Ketika seorang wanita tidak dapat memenuhi standar kecantikan yang diterapkan dalam masyarakat, besar kemungkinan mereka dihinggapi rasa tidak nyaman, kesepian, terasing, dan rasa percaya diri yang rendah (Wolf, 2004:24). Kenyataan tersebut menegaskan bahwa kita sedang berada dalam pertentangan melawan salah satu bentuk diskriminasi yang menggunakan citra kecantikan sebagai senjata untuk menentang kemajuan wanita. Inilah yang selama ini disebut sebagai mitos kecantikan. Dalam bahasa yang lebih sederhana, mitos kecantikan menggunakan citra kecantikan untuk menentang kemajuan perempuan (Wolf, 2004:24).

Konsep kecantikan yang dilekatkan terhadap tubuh wanita tidak hanya terjadi dalam dunia nyata tetapi juga dalam karya sastra. Mitos kecantikan membentuk interpretasi kepada wanita dalam kakawin Smara Tantra yang dianalisis. Masalahmasalah tersebut pada akhirnya bertujuan untuk menjelaskan mitos kecantikan dalam kakawin Smara Tantra, serta untuk membentuk interpretasi wanita dan mendeskripsikan pengaruh mitos kecantikan terhadap wanita. Tulisan ini diharapkan dapat berpartisipasi dalam rangka memperluas cakrawala interpretasi para pembaca sastra dalam memahami kakawin Smara Tantra dengan sudut pandang feminisme, khususnya pada mitos 
kecantikan yang disampaikan oleh Naomi Wolf.

\section{TEORI}

Dalam tulisan ini menggunakan teori mitos kecantikan yang dipopulerkan oleh Naomi Wolf. Wolf menjadi salah satu penggerak dalam gerakan feminisme Amerika. Buku karya Wolf yang paling terkenal yaitu berjudul "the Beauty Myth: How Images Of Beauty Are Used Againts Women (1991)". Definisi mitos kecantikan mengawali tulisannya, Wolf menggambarkan keberhasilan gerakan feminisme dalam meraih hak-hak hukum dan reproduksi, disamping mendapatkan pendidikan ke jenjang yang lebih tinggi (Wolf, 2004: 23). Para wanita mulai memberi perhatian khusus terhadap hal-hal semacam penampilan fisik, tubuh, wajah, rambut, atau pakaian. Hal ini membawa mereka pada pertentangan pemahaman antara kebebasan dan kecantikan wanita (Wolf, 2004:24). Mitos kecantikan mengintimidasi wanita melalui jalan yang demikian sistematis dan terorganisasi. Selama wanita berpikir bahwa menjadi cantik sesuai dengan representasi kacamata masyarakat adalah satu kebutuhan yang mutlak, mitos kecantikan akan selalu membelenggu (Wolf, 2004:8). Berkaitan dengan kecantikan wanita, Wolf menyatakan bahwa perempuan tampil cantik sejatinya diperuntukkan kepada kaum laki-laki.

Mitos kecantikan juga dapat dilihat dalam ruang kebudayaan. Mitos kecantikan sangat lekat dengan kebudayaan. Wanita selalu diposisikan sebagai makhluk yang dinilai oleh kaum laki-laki. Munculnya stereotip tentang wanita diciptakan agar semakin dekat dengan mitos kecantikan yang membuat seorang wanita hanya memiliki dua pilihan yaitu "memiliki pikiran" atau "memiliki kecantikan". Sejatinya mitos kecantikan mulai ditanamakan sejak kecil kepada kaum wanita melalui teks, cerita atau dongeng yang telah diciptakan dengan memunculkan kesan maskulinitas atau machoisme. Mitos kecantikan juga disisipkan dalam konteks religiusitas. Pengontrolan tubuh wanita dalam tatanan masyarakat yaitu dengan menggunakan religiusitas. Sering kali dalam konteks religiusitas, tidak mendukung keterlibatan wanita dalam dunia publik terutama pada agama patriarkal. Agama patriarkal telah berhasil mengontrol seksualitas kaum wanita dengan memunculkan berbagai macam mitos-mitos tentang seksualitas wanita. Moralitas seorang wanita diukur melalui tubuh dan seksualitasnya. Konstruksi mitos kecantikan yang telah membelenggu kaum wanita menjadikan wanita tidak lagi menghormati dirinya dan mengabaikan kenikmatan seksualitas wanita.

Dasar pemikiran feminisme dalam penelitian sastra adalah upaya pemahaman kedudukan peran wanita seperti yang tercermin dalam karya sastra (Sugihastuti \& Suharto, 2002:15). Dalam paradigma perkembangan kritik sastra, kritik sastra feminisme dianggap sebagai kritik yang bersifat revolusioner yang ingin menumbangkan wacana dominan yang dibentuk oleh suara tradisional yang bersifat patriarkal (Ruthven dalam Wiyatmi, 2012:44). Tujuan utama studi sastra feminis adalah menganalisis relasi gender, situasi ketika wanita berada dalam dominasi lakilaki (Flax dalam Wiyatmi, 2012:44). Melalui feminisme, perempuan yang terdapat dalam karya sastra akan dideskripsikan (Humm dalam Wiyatmi, 2012:22). Kritik sastra feminis melakukan rekonstruksi dan membaca kembali karya-karya tersebut dengan fokus pada wanita, sifat 
sosiolinguistiknya, dan mendeskripsikan tulisan wanita dengan perhatian khusus pada penggunaan kata-kata dalam tulisannya (Humm dalam Wiyatmi, 2012:22). Adapun karya sastra yang dimaksudkan dalam tulisan ini adalah kakawin Smara Tantra.

\section{METODE PENELITIAN}

Metode diawali dengan pengumpulan data sangat menentukan berhasil atau tidaknya suatu penelitian (Bungin, 2001: 129). Tulisan ini bersifat kualitatif dengan objek penelitian ini adalah isi dari teks kakawin Smara Tantra. Untuk memperoleh data dilakukan dengan metode simak yang disertai dengan teknik catat karena objek yang diteliti tersebut berupa bahasa yang sifatnya teks. Langkah selanjutnya dilakukan pencatatan tentang data yang akan dipakai mendukung analisis. Data yang diambil dari teks kakawin Smara Tantra tersebut merupakan data primer. Analisis data merupakan proses menelaah seluruh data hasil penelitian yang diperoleh melalui pengamatan, pencatatan, dokumen, dan sebagainya (Moleong, 1990: 199). Hasil penelitian ini akan disajikan dengan menggunakan metode informal karena data yang dikaji adalah data kualitatif dalam bentuk naratif verbal. Metode informal artinya cara penyajian hasil pengolahan data penelitian dengan menggunakan rangkaian kata atau kalimat sebagai sarat penyajian (Sudaryanto, 1992: 64), implikasinya tidak akan memakai rumusan angka-angka, diagram, dan grafik, yang masih memerlukan penjelasan lagi.

\section{Mitos Kecantikan Tubuh Wanita Dalam Kakawin Smara Tantra}

Lontar kakawin Smara Tantra ini berisi tentang pengetahuan dalam merasakan kenikmatan cinta sekaligus seksualitas. Selain itu, juga berisi tentang ciri-ciri wanita, bentuk tubuhnya, gayanya secara baik dan buruk seorang wanita. Secara etimologi kakawin Smara Tantra berasal dari bahasa Sanskerta yang telah diserap kedalam bahasa Jawa Kuna (Hybrida Sanskerta atau Bahasa Sanskerta Kepulauan/ Nusantara). Berasal kata kakawin yang berarti puisi Jawa Kuno, kata Smara berarti cinta, dewa cinta (Zoetmulder, 2004:1109). Sedangkan Tantra berarti ajaran, tuntunan (Zoetmulder, 2004:1202). Jadi kakawin Smara Tantra adalah puisi Jawa Kuno yang berisi ajaran dan tuntunan dalam bercinta. Zoetmulder (2004:1110) menyatakan bahwa Smara Tantra sama dengan ajaran Kāma Tantra. Kakawin Smara Tantra sesungguhnya memberikan pemahaman dan pengetahuan terhadap percintaan dengan wanita. Karena dengan memahami ajaran bercinta dan setelah menemukan kerahasiaan dalam bercinta, maka kesucianlah yang akan didapatnya.

Wanita diciptakan oleh Ida Sang Hyang Widhi Wasa lengkap dengan pesona kecantikannya, sehingga banyak orang menyatakan bahwa kelahiran sebagai seorang wanita memiliki kecantikan yang luar biasa, bisa menaklukkan hati para lelaki. Jika lelaki identik dengan kuat, kasar, dan maskulin, wanita justru lemah lembut, halus, feminim dan cantik. Kecantikan tersebut meliputi luar dan dalam, cantik rupa dan budi yang berasal dari karakter hati dan fisik. Sesungguhnya dalam teks-teks kesusastraan Hindu lebih mengutamakan pesona kecantikan dari dalam (inner beauty) daripada kecantikan fisik karena hati adalah komandan yang akan menentukan baik buruknya perilaku seorang wanita. Ciri-ciri hati yang cantik bagi seorang wanita antara lain terbebas dari sikap sombong, tamak dan 
dengki, dan dipenuhi dengan sifat kebijaksanaan. Lebih lanjut dalam dalam kakawin Smara Tantra dijelaskan, sebagai berikut.

"Yan stri swara nika madalem manohanara ya komala malilang harum, mwang wongkun lidah katar majimbar adawarddha malungid araras, byakta manis I wacana jiwa nadra kagaway swari talinga nuti,yeka metu-metu sukha bhagya bhoga winangunnya kahajaran ika"

Artinya:

Jika cara bicara wanita itu pelan dan penuh kelembuatan maka ia akan sebarkan keharuman, la dapat mengatur lidah dengan tanpa diwarnai oleh ketajaman perkataan membuat kesan yang baik, terlihat manis ucapan pertanda jiwa wanita itu cantik apalagi ia mudah memahami orang lain, wanita yang demikian akan wujudkan kebahagiaan dan kenikmatan melalui ucapannya (Kakawin Smara Tantra, Wirama VII.9).

\section{Kutipan teks dalam kakawin Smara}

Tantra di atas menjelaskan seorang wanita memiliki kelebihan dalam berbicara. Berbicara sebagai seorang wanita haruslah pelan dan penuh kelembutan. Dengan berbicara seperti itu, sesungguhnya seorang wanita sedang menyebarkan keharuman dirinya dan memiliki tanda bahwa jiwa wanita itu cantik sehingga mampu mewujudkan kebahagiaan dan kenikmatan melalui ucapan yang disampaikannya. Konstruksi dan mitos yang diciptakan dalam penggalan teks di atas memberikan asumsi bahwa seorang wanita harus mampu berbicara dengan pelan dan lembut maka kecantikannya akan terpancarkan. Namun apabila sebaliknya, jika seorang wanita berbicara dengan nada yang tinggi dan keras tidak akan memancarkan kecantikan dalam diri wanita tersebut. Dari teks ini, kemudian dapat dianalisis bahwa sudah terdapat sebuah konstruksi mitos kecantikan melalui ucapan seorang wanita dalam teks kakawin Smara Tantra. Lebih jauh, pada teks kakawin Smara Tantra, juga menjelaskan ucapan yang hendaknya diucapkan oleh seorang wanita yaitu sebagai berikut.

"Stri yar kuning lidhah ika alpa ajarnya darppa, darppa wicara tan apik musuha wisudha, śuddhajaring lidhah awas yadi rakta warnna, warnnanya marsik adhawa rjja mahottama"

Artinya:

Jika lidah wanita itu kecil dan kuning, pertanda jika berbicara menyenangkan hati tidak suka memojokkan lawan bicaranya, kejujuran ucapan wanita nampak pada lidahnya yang berwarna merah, warnanya bersih dan panjang sangat cantik dan indah (Kakawin Smara Tantra, Wirama VII.4).

\section{Melalui teks kakawin Smara Tantra} di atas, menyatakan tentang ciri-ciri lidah seorang wanita. Jika lidah wanita yang kecil dan berwarna kuning, maka wanita tersebut saat berbicara akan menyenangkan hati dan tidak suka memojokkan lawan bicaranya. Sedangkan jika lidah wanita berwarna merah, bersih, cantik dan indah maka wanita tersebut dalam ucapannya akan selalu disertai dengan kejujuran. Selain menyebutkan ciri-cirinya, dalam kakawin Smara Tantra juga menyertakan sikap dan tingkah laku yang melambangkan kecantikan dari dalam diri (inner beauty) seorang wanita melalui lidahnya. Mitos kecantikan yang terbentuk melalui lidah seorang wanita yang 
disebutkan dalam kakawin Smara Tantra secara tidak langsung membuat seorang wanita akan membandingkan dan memerhatikan bentuk lidahnya sendiri.

Kakawin Smara Tantra mengajarkan bahwa menemukan kecantikan wanita adalah hal yang sangat penting. Hal ini sejatinya jika ditelisik lebih jauh akan menguntungkan kaum patriarki saat memilih istri atau pasangannya. Seperti yang dijelaskan pada salah satu kutipan teks kakawin Smara Tantra, memaparkan tentang bagaimana pentingnya menemukan kecantikan wanita. Kecantikan wanita dapat dilihat melalui sikap lemah lembut dan anggunnya seorang wanita ketika berbicara. Hal ini kemudian dapat diumpamakan sebagai seekor angsa. Apabila dilihat dari segi semiotika, seekor angka memiliki makna dan melambangkan keanggunan, kecantikan dan keindahan yang memiliki aura putih bersih. Sehingga kemudian seorang wanita dapat diibaratkan sebagai seekor angsa yang mampu memikat hati orang ketika melihatnya dan sangat ingin memilikinya. Adapun kutipan teksnya adalah sebagai berikut.

"Kapangguh iling hayuning wara stri, wara stri ya ajeng komala lūd sasohba, saśobha dening wuwusnya, wuwusnya himper kagha cakrawaka"

Artinya:

Menemukan kecantikan wanita adalah hal yang penting, wanita yang normal adalah wanita yang cantik, lemah lembut dan anggun, anggun karena ucapannya yang indah, seperti seekor angsa" (Kakawin Smara Tantra, Wirama $\mathrm{X} .1)$.

Jika dilihat dengan seksama isi kutipan teks diatas menjelaskan bahwa seorang wanita yang normal adalah wanita yang cantik, lemah lembut dan anggun. Dari kutipan tersebut memunculkan mitos bahwa wanita yang normal adalah wanita cantik yang lemah lembut dan anggun sifatnya. Melalui teks ini kemudian seorang wanita menjadi terbelenggu akan konstruksi mitos kecantikan yang secara tidak langsung menyatakan wanita yang tidak memiliki sifat lemah lembut dan tidak anggun bukannlah wanita yang normal dan tidak cantik. Hal ini sangat sesuai dengan mitos kecantikan yang dijelaskan oleh Naomi Wolf bahwa seorang wanita menjadi terbelenggu akan konsep cantik yang hanya dilihat dari kacamata masyarakat terutama pada kaum patriarki saja. Secara mendalam perumpamaan seekor angsa kembali dipertegas oleh pengawi "pengarang" pada teks kakawin Smara Tantra wirama XI bait 1-2, sebagai berikut.

"Wakya lilang Iwir kadi angsa moni, mening wayyoneng masěnĕng suramya, ramya laloh towi sĕdhĕng saharsa, harsa siwo wetnya saraga sasri"

Artinya:

Wanita yang bersih tampak seperti angsa yang tidak pernah kemana-mana, dalam kejernihan air yang tenang dan sedang bercinta segalanya akan terasa indah, keindahan pesona wanita terpancar apabila sedang dalam kepuasan, puas dalam permainan cinta sebabnya telah dikuasai nafsu yang bergelora.

"Sasri lingling stri kadi soyya sabda, sabdanya mangděha hayu lot wawanya, wani ta nawang kokila nandhaning stri, stri mangkāna jarnya samasta harjja" 
Artinya:

Indah cara pandang wanita penuh perhatian seperti sang surya yang berbicara, cara bicaranya sangat lah cantik dan penuh dengan kesabaran, wanita yang sabar tampak seperti burung elang yang berkicau, wanita yang demikian itu ucapannya sopan dan santun.

Pada kutipan wirama XI bait 1-2 dalam kakawin Smara Tantra di atas, menjelaskan wanita yang diperumpamakan sebagai seekor angsa dalam kejernihan air yang tenang. Ini merupakan wujud keindahan dari pesona kecantikan wanita yang terpancar. Terpancar jika sedang dalam keadaan bercinta, merasakan puas dalam permainan cinta dan karena nafsu yang bergelora. Pengawi "pengarang" sangat cerdas dalam menggambarkan pesona kecantikan wanita dalam bercinta, sebagai akibat gelora nafsu yang membara. Pengawi kakawin Smara Tantra menjelaskan gelora nafsu yang membara dalam pandangan wanita yang penuh perhatian layaknya sebagai Sang Surya yang sedang berbicara. Sangat cantik dan penuh dengan kesabaran. Kesabarannya itu diibaratkan burung elang yang berkicau mempesona akibat ucapannya yang sopan santun.

Dari teks di atas juga tergambarkan bagaimana konstruksi mitos kecantikan telah mengontrol seorang wanita tentang seksualitasnya. Moralitas seorang wanita tergambarkan melalui kecantikan yang dilihat saat keadaan bercinta. Sehingga sering kali wanita tidak menghormati dirinya dan mengabaikan kenikmatan sesualitasnya agar tetap memunculkan aura kecantikannya. Tidak hanya pada ucapan dan tingkah laku yang di deskripsikan dalam kakawin Smara Tantra, tetapi juga bagaimana karakter wanita yang dapat dilihat melalui penglihatannya. Pada wirama XV kakawin Smara Tantra menggambarkan wanita sebagai berikut.

"Kadi cakrawala sawang ing wanita aksi, kadi sarppa caksa anawar i samāksi, kadi kakak netra nakulopama ngaksi, kadi mangkān laksanā i kottamang aksi"

Artinya:

Seperti burung elang pengelihatan wanita, seperti mata ular membuat luluh mata sang lawan, seperti mata gagak mirip pengelihatannya, seperti itu lah perumpamaan pesona pengelihatan wanita.

Teks kakawin Smara Tantra diatas menjelaskan bahwa penglihatan wanita itu sangat tajam seperti elang, membuat luluh seperti mata ular, indah seperti gagak, maka seperti itu sesungguhnya perumpamaan penglihatan wanita. Pengawi melihat itu sebagai pesona kecantikan yang dimiliki seorang wanita. Menggambarkannya dalam keindahan mata burung. Karangan pengawi tersebut memikat hati dan jiwa, masuk kedalam alam pikiran yang membangkitkan imajinasi pembaca untuk memahami pesona kecantikan seorang wanita. Tidak hanya membangkitkan imajinasi, teks diatas juga memuat mitosbagi kaum wanita tentang pesona penglihatan wanita yaitu memiliki mata yang tajam mempesona dan dapat membuat luluh hati bagi yang menatapnya.

Pesona kecantikan yang dipahami dalam ajaran kakawin Smara Tantra, sesungguhnya lebih jauh mengaitkan kecantikan fisik dengan kepribadian, sifat dan kebaikan hati. Kemudian mengemasnya sedemikian rupa menjadi satu paket, sehingga menariknya seorang wanita bagi para lelaki. Dalam tren dunia sekarang mitos kecantikan wanita akan selalu melekat dengan perilakunnya sehingga disebut 
sebagai the strength of a woman dalam memberikan warna-warni kehidupan bagi para lelaki. Sebagaimana ajaran yang telah disampaikan oleh sang pengawi kakawin Smara Tantra dalam menyatakan tujuannya mengarang adalah untuk menjunjung semua peraturan sebagai wujud kecantikan hati, hingga berani berkorban untuk pujaan hati tanpa perasaan egois terasa demikian indah, itu sebabnya mengarang tentang kecantikan wanita.

Namun dibalik karangan teks kakawin Smara Tantra yang dibuat oleh pengawi, sejatinya telah menyimpan berbagai macam mitos-mitos kecantikan. Mitos tersebut membelenggu kaum wanita tentang konstruksi cantik sebagaimana yang telah dibangun dan digambarkan dalam teks-teks kakawin Smara Tantra. Mitos kecantikan yang dimuat telah mengintimidasi kaum wanita tentang kecantikan menjadi suatu kebutuhan yang mutlak dan hanya diperuntukkan bagi kaum patriarki saja. Kaum wanita diibaratkan dan diharuskan untuk menciptakan stereotip baik dan layak untuk dimiliki dan diminati oleh kaum laki-laki. Pengontrolan tubuh seperti yang dijelaskan pada teori mitos kecantikan Naomi Wolf telah mengarah pada konteks seksualitas dari segi patriarki. Sebab pada kakawin Smara Tantra yang cukup terkenal pada kalangan masyarakat Bali hanya melihat dari sudut pandangan kaum laki-laki atas konstruksi cantik wanita. Jika dikaitkan dengan masa sekarang konstruksi cantik tidaklah relatif bagi setiap individu sebab cantik tidak hanya dilihat dari segi fisik (tubuh) namun juga dapat dilihat dari sikap dan karakternya.

\section{Tubuh Wanita Sebagai Objek Seksualitas Dalam Kakawin Smara Tantra}

Seksualitas merupakan keadaan manusia mendapatkan pengalaman erotis dan mengekspresikan dirinya sebagai makhluk hidup seksual; kesadaran hakekat diri sebagai laki-laki atau perempuan; kapasitas yang mereka miliki atas pengalaman erotis dan tanggapan atas pengalaman itu. Seksualitas manusia dapat dijelaskan bagaimana sesorang tertarik oleh orang lainnya yang berlawanan jenis kelamin "heteroseksualitas" kepada yang sejenis "homoseksualitas", kepada semua jenis "biseksualitas" atau tidak tertarik sama sekali "aseksualitas". Penggunaan istilah seks dan seksualitas merupakan suatu hal yang berbeda. Leksikon seks sering digunakan dalam dua cara, pertama seks digunakan untuk mengacu pada bagian fisik dari berhubungan (aktivitas seksual genital). Kedua, seks juga digunakan untuk memberi label gender, baik seseorang itu pria atau wanita (Zawid, dalam Perry \& Potter 2005). Seksualitas adalah istilah yang lebih luas. Seksualitas diekspresikan melalui interaksi dan hubungan dengan individu dari jenis kelamin yang berbeda dan mencakup pikiran, pengalaman, pelajaran, ideal, nilai, fantasi, dan emosi. Seksualitas berhubungan dengan bagaimana seseorang merasa tentang diri mereka dan bagaimana mereka mengkomunikasikan perasaan tersebut kepada lawan jenis melalui tindakan yang dilakukannya, seperti sentuhan, ciuman, pelukan, dan senggama seksual, serta melalui perilaku yang lebih halus, seperti isyarat gerakan tubuh, etiket, berpakaian, dan perbendaharaan kata (Zawid dalam Perry \& Potter, 2005).

Kakawin Smara Tantra menjelaskan seksualitas merupakan sebagai ajaran yang rahasia. Ajaran tersebut menghantarkan 
orang yang mempelajarinya mendapatkan kesempurnaan dan mampu memusnahkan penyebab kesengsaraan. Adapun kutipan teks pada bagian awal kakawin Smara Tantra menjelaskan sebagai berikut.

"Sang sampun krta tattwa ning wisaya suddha tumĕmu-tĕmu sandhi ning smara, ngkaneng Madhya ikang tilam ri huwus ing ulaha nekan i samprayojana, kāma děha sinamādhi sakāla saha yoga dhāraka, siddha mangguhaken rasa mrĕtta wisesa panggilanga wikalpa karana"

Artinya:

Orang yang sempurna
dalam ajaran bercinta nampak
suci telah menemukan rahasia dalam
bercinta, selesai atas melakukan
hubungan
memperoleh dan
pengetahuan akan asmara pemusatan
pikiran dan pengendalian, agar
berhasil mencapai kepuasan (rasa)
yang tak terhingga yang mampu
memusnahkan
kesengsaraan" (Smara Tantra,
Wirama I.1).

Kutipan teks diatas menjelaskan secara spesifik bahwa bagi seseorang wanita yang telah menemukan rahasia dalam bercinta akan menemukan kesempurnaan yang suci. Kesucian dalam melakukan hubungan seksualitas memperoleh kenikmatan dilakukan dengan cara memiliki pengetahuan asmara, memusatkan pikiran dan mampu mengendalikannya agar berhasil mencapai kepuasan tertinggi dan mampu memusnahkan penyebab kesengsaraan. Dapat dipahami Lontar Kakawin Smara Tantra memberikan pengajaran sesungguhnya seksualitas itu indah.
Keindahan itu akan tercapai, jika seksualitas itu didasari dengan dasar pengetahuan asmara, ditambah dengan pemusatan pikiran serta mampu melakukan pengendalian agar mampu mencapai kepuasan rasa. Rasa yang dimaksud melebihi pertemuan kenikmatan persenggamaan, namun rasa kenikmatan dengan kosmik sehingga mampu memusnahkan penyebab kesengsaraan. Lebih lanjut dalam teks kakawin Smara Tantra menjelaskan tentang pengeksploitasian bentuk tubuh wanita dalam melakukan persenggamaan "seksualitas". Adapun teksnya, sebagai berikut.

"Yan sroni pwa maha
wiwrddhi manulus sthīra pagěh
śobhita, drawyaniārja māgeng
mahottama tikang stri mangkāna
kaweruhi, len tang stri jagathananya
mās ikara tan mwang madya mageng
nika, lūd mandita i roma manwam
araras yan mangkānang striyottama"

Artinya:

Jika bagian kewanitaannya itu sempurna berarti ia sangat tulus dalam temukan kenikmatan bercinta, Kemaluan wanita yang besar sangat berarti, Beda pula wanita yang memiliki pinggul besar, hal itu merupakan kelebihannya apalagi disertai dengan bagian kewanitaan yang besar tadi, begitu pula jika dihiasi oleh bulu maka akan tercipta keindahan demikian lah seorang wanita yang sempurna" (Kakawin Smara Tantra, Wirama II.2).

"Muwa hana tang stri mademit i kuksi, lituhayu sakweh wĕkas niarja, hayata yusa ya ajar i kawi śuddha, kinahananing bhoga lanā sukhanya" 
Artinya:

Dan ada istri (wanita) yang langsing perutnya, menarik dari segala hal berarti ia pembawaannya baik, usaha wanita di dalam merubah kehidupannya digambarkan sebagai pujangga suci, agar ia dipenuhi oleh kenikmatan bercinta yang abadi sehingga membuat lelaki merasa senang (Kakawin Smara Tantra, Wirama II.3).

Kājar yadin talukan hilatangka, tangkanikang taluka mangkā diwya, diwya mangun kottama buddhi lila, lilang manah swarga mawas kapangguh"

Artinya:

Biasanya jika lidah wantia itu menempel hingga langit-langit mulut, maka jika berciuman akan terasa demikian indah, keindahannya munculkan rasa kedamaian, kedamaian hati serasa berada di surga" (Kakawin Smara Tantra, wirama IX.3).

Berdasarkan beberapa kutipan teks kakawin Smara Tantra diatas menggambarkan eksploitasi bentuk tubuh wanita sebagai objek seksualitas. Seksualitas yang disertai dengan ciri-ciri bentuk tubuh wanita adalah bentuk eksploitasi kecantikan wanita oleh laki-laki yaitu pengawi "pengarang" kakawin Smara Tantra. Teks pertama menjelaskan bahwa wanita terlihat sempurna dalam menikmati percintaan, jika kemaluan wanita itu besar berisi bulu dan terlebih lagi ditambah dengan pinggul yang besar maka akan menciptakan keindahan. Itu adalah kelebihan bagi seorang wanita dan menjadikannya terlihat sempurna.
Kesempurnaan itu dijelaskan lebih lanjut pada teks kedua dengan bentuk perut yang langsing, sehingga menarik untuk dilihat dengan indah. Bagaikan seorang pujangga suci yang mampu membius para pembaca dengan keindahan karya sastranya, maka seperti itulah seorang wanita yang mampu menarik hati, menciptakan keindahan melalui bentuk tubuhnya, dan membuatkan kenikmatan dalam bercinta. Bercinta yang indah membuat lelakinya menjadi senang dan bahagia. Ciri-ciri yang dijelaskan oleh pengawi tersebut menandakan bahwa prosesi penciptaan kakawin Smara Tantra ini, sang pengawi melakukan pengamatan dan pendalaman terhadap bentuk tubuh wanita. Eksploitasi tubuh wanita ini mampu membius pengawi sehingga mampu menuliskannya dalam bentuk karya sastranya dan menandakan bahwasanya pengawi telah melakukan riset mendalam dengan banyak wanita, sehingga terjadi ketidaksetaraan gender, dan wanita menjadi korban atas objek seksualitas tersebut.

Teks ketiga menggambarkan bahwa permainan seksualitas diawali dengan berciuman. Berciuman dengan lidah wanita itu harus menempel hingga langit-langit mulut maka titik kenikmatan dan keindahan itu menimbulkan rasa damai. Damai seperti berada di surga maka berciuman dengan seorang wanita seperti itulah lah rasanya. Ajaran Smara Tantra ini mengarahkan dan menuntun pembaca untuk dapat mencari wanita yang mampu atau pandai dalam titik kenikmatan bercinta dengan diawali dengan perciuman. Perciuman ini akan meningkatkan gairah asmara sensual bagi laki-laki, dan wanita wajib bisa melakukan hal tersebut agar dapat dilanjutkan pada bagian eksekusi percintaan. 
Berdasarkan ketiga kutipan teks di atas tergambarkan cukup jelas bagaimana tubuh wanita dan seksualitasnya digambarkan. Objek sesksualitas yang bertitik pada tubuh wanita seolah-olah mengeksploitasi kaum wanita tentang seksualitasnya. Pengambaran sensual hubungan bercinta lebih berfokus kepada kaum wanitanya. Sehingga bagi kaum perempuan yang telah membaca teks ini akan terkonstruksi pemikirannya agar mampu menyerupai bentuk tubuh dan gairah seksualitas yang sama seperti isi teks kakawin Smara Tantra. Kaum wanita akan lebih berfokus pada konstruksi mitos yang telah dibuat oleh pengarang teks kakawin Smara Tantra ketimbang ketikmatn yang di dapat saat bercinta. Inilah kemudian yang disebutkan oleh Naomi Wolf bahwa wanita tidak lagi menghormati dirinya sendiri ketika sudah terbelenggu akan konstruksi mitos kecantikan.

Sang Pengawi mampu melukiskan keindahan (kelangen) tubuh dari seorang wanita pada karya sastranya. Keindahan itu alami seperti bunga yang indah dan harum memikat lebah untuk mencari madunya, maka seperti itulah wanita memikat untuk menggairahkan gelora asmara lelaki. Bunga dan tubuh wanita seperti telah ditakdirkan untuk menyatu, membangun sebuah keindahan, mencapai kebersamaan menjadi satu dalam gelora asmara percintaannya. Tampil cantik dengan laksana dewati (para bidadari atau para dewi) tentu dapat mengikat setiap pasang mata yang memandangnya. Keindahan tubuh wanita akan terlihat sangat elok jika wanita selalu menjaganya. Menjaganya dengan merias diri seperti teman sejatinya agar selalu menjaga pesona kecantikannya (inner beauty). Dengan menjaga pesona kecantikannya akan membangun hubungan bagus dalam seksualitasnya. Gelora asmara melandasinya dan menjadi dasar membius lawannya. Lebih mendalam teks kakawin Smara Tantra menjelaskan, sebagai berikut.

"Yan stri kottama warnnaning stana nika tyanteng wiwrddhya annulus, sor niyu danta kulitnya manwam araras matwas tuwunya makĕg, śobha hrit marupit tanemnya mabuka jarnya sāda ngdhe sukha, lūd swaminya maha yusanya madawa nggeng ramya nitya langö"

Artinya:

Wanita yang demikian juga memiliki jenis payudara yang besar maka bertambah sempurna ia, sisi bagian bawah (vagina) kulitnya biasanya terlihat awet muda dan mempesona, sehingga dalam bersenggama akan timbulkan suara desahan yang keras, terasa nikmat jika bagian itu menyempit sehingga susah memasukkannya (alat vital pria) dan jika membuka sedikit teramat sangat menyenangkan, ditambah pula alat vital prianya berdiri, sangat panjang dan membesar maka sangat menggairahkan" (Kakawin Smara Tantra, Wirama XVII.3).

Kutipan teks kakawin Smara Tantra diatas menggambarkan seksualitas. Wanita yang sempurna perspektif kakawin Smara Tantra selain memiliki kemaluan yang berbulu, pinggul besar, dan perut langsing, juga dijelaskan secara mendalam memiliki payudara yang besar, maka akan bertambah sangat sempurna wanita tersebut. Sempurna wanita tersebut sangat menggairahkan jiwa dan menggentarkan hati dalam prosesi percintan dan seksualitas. Seksualitas terjadi dengan persenggamaan 
maka akan timbul suara desahan yang keras. Karena ciri-ciri wanita tersebut memberikan kenikmatan dalam prosesi sanggama, dimulai dari memasukan pada kemaluan wanita itu terasa sempit sehingga susah memasukkannya dan jika membukanya sedikit sangat menyenangkan dan nikmat. Apalagi alat vital laki-laki itu berdiri, panjang dan membesar (mengeras) maka titik pertemuan sanggama tersebut akan sangat menggairahkan dan memberikan keindahan, kenikmatan dunia. Pengeksploitasian bentuk tubuh wanita sebagai objek seksualitas yang memuaskan dalam kakawin Smara Tantra sesungguhnya mengarahkan untuk melihat dan memandang wanita agar sesuai dengan ciri-ciri yang disampaikan dalam teks tersebut, guna untuk mendapatkan kenikmatan bercinta atau bersanggama. Kakawin Smara Tantra mengarahkan pembaca untuk memahami wanita baik melalui kharateristiknya, ciri-cirinya, bentuk tubuh wanita yang menyebabkan pesona kecantikan (mitos), dan bentuk tubuhnya untuk mendapatkan keindahan seksualitas. Titik krusial kenikmatan dieksploitasi dengan sangat menarik dan indah bagi pembaca.

\section{Kuasa Hegemoni Pengawi Dalam Teks Kakawin Smara Tantra}

Kuasa hegemoni pengawi telihat dalam kakawin Smara Tantra, melalui penjelasan tujuan mengarang kakawin tersebut dan menggambarkan kharakteristik wanita. Kuasa hegemoni itu mendorong pengawi mengarang tentang kebaikan dan keburukan dalam memilih seorang wanita. Pengawi secara tidak langsung menyatakan citra seorang wanita memiliki citra yang baik dan citra yang buruk. Tentunya penggambaran sosok seorang wanita yang ideal, budi luhur, cantik hati, dan patut diteladani, atau wanita yang reputasinya jelek karena perilaku tidak sesuai dengan ajaran agama, moralitas, dan kesusilaan dinyatakan secara jelas dalam lanjutan bait kakawin Smara Tantra. Pengelompokkan citra yang dilakukan oleh seorang pengawi dalam kakawin tersebut merupakan bentuk diskriminasi terhadap wanita karena kebenarannya belum bisa dibuktikan. Uniknya citra wanita yang buruk ditambahkan dengan kharakteristiknya dan disarankan untuk tidak memilihnya. Kuasa hegemoni itu telah mendeskriditkan wanita yang memiliki ciri-ciri kharakteristik seperti itu. Teks kakawin Smara Tantra dengan jelas menyatakan itu, adapun sebagai kutipan berikut ini.

"Hana wanita Iwir mahisa lakunya, hana kadi lampah ningiba lakunya, hana sumameng angsa gati lakunya, hana manawang mahisa lakunya"

Artinya:

Ada wanita yang jalannya seperti kerbau, ada yang jika berjalan seperti akan jatuh, ada yang pikirannya putih bersih berarti indah perbuatannya, ada yang seperti kerbau berarti ia suka bingung" (Kakawin Smara Tantra, Wirama III.1).

"Mahrit mālit dahat ikang stāna kājarnya, Nirsuddha laksāna nika tiśayeng daridra, lud mālit ing stāna tuwin salaya pādohan, Byakte kinasaweak naga sĕnĕngnya sigrha"

Artinya:

Jika buah dada wanita kecil dan mengkerut, pertanda ia tidak perawan dan itu terasa menyedihkan, selain kecil buah dadanya juga letaknya berjauhan satu dengan yang lain, jelas bahwa perlakuannya kasar seperti 
naga sehingga kekasihnya akan meninggalkannya" (Kakawin Smara Tantra, Wirama IV.3).

\section{Kutipan kakawin Smara Tantra} diatas menjelaskan bahwasanya kuasa hegemoni pengawi masuk kedalam pengarangan teks tersebut. Mendeskriditkan wanita dengan memiliki ciri-ciri seperti teks pertama dinyatakan wanita ada yang berjalan seperti kerbau maka ia akan sering jatuh, dan ada pemikirannya seperti kerbau yang suka bingung. Kemudian jika dilanjutkan pada teks selanjutnya dijelaskan lagi ciri-cirinya jika wanita memiliki payudara kecil, letaknya berjauhan dan mengkerut itu tandanya wanita tersebut sudah tidak perawan sekaligus terasa menyedihkan, serta menandakan prilakunya kasar. Tentunya apa yang disampaikan oleh pengawi itu pada kakawin Smara Tantra belum tentu bisa dipastikan kebenarannya, terlebih lagi untuk memahami wanita butuh proses yang lama, interaksi sosial antar individu manusia. Terlepas dari apa yang disampaikan pengawi tersebut juga mengindikasikan pengawi adalah seorang laki-laki yang berada dipuncak (mendominisasi) dan terjadi ketidaksetaraan gender.

Mitos kecantikan menjadi hal mutlak bagi laki-laki untuk menilai bagaimana wanita itu, apakah akan memuji atau mendeskriditkannya. Lebih mendalam kuasa hegemoni pengawi berlanjut dengan mengomentari ciri-ciri fisik wanita. Dalam perkembangan jaman sekarang dikenal dengan istilah body shaming. Body shaming adalah tindakan mengomentari bentuk fisik seseorang. Entah itu disengaja atau tidak, namun hal ini bisa berpengaruh ke masalah mental orang yang dikomentari. Body shaming yang terdapat dalam teks kakawin
Smara Tantra jelas mendeskriditkan wanita, terlebih lagi ciri-ciri fisik tersebut dijelaskan sangat detail seperti pada beberapa kutipan teks kakawin Smara Tantra berikut ini.

"Malwa midhay gigir ikang wanita nirarja, iyan tang lebak-lebak i keringan ing gigirnya, ring madhyaning ngĕla hula nugĕla maner ya, rweka swabhāwa nika dāsa dumadya chihna"

Artinya:

Malu rasanya jika punggung wanita tidak halus, banyak terdapat lubanglubang kering pada pungguhnya, di tengahnya ada garis-garis (selulit) yang memperburuk keadaan punggung, dua hal itu merupakan petunjuk sepuluh sifat perubahan wanita untuk menjadi budak" (Kakawin Smara Tantra, Wirama IV.5).

"Stri ya melad-melad apes tipi sing hilatnya, bwat buddhi rosa tukaran pwa kājar hina, yapwan stri ya cěndhek i lidahnya kadi pwa punggel, tunggal mamahnya kājar tukaran makambĕk"

Artinya:

Jika lidah wanita tipis, lebar dan panjang, susah untuk memahami sebuah kesalahan karena itu ia mudah marah,dan bila lidah wantia pendek seolah putus, mudah memahami bahwa kemarahan adalah penyebab pertengkaran" (Kakawin Smara Tantra, Wirama VIII.2).

"Kedwa mangun halā jar ika yan stri subha tutuk ika, kandel ika bupak bĕlah i sor ruhur i wajah makeb, 
kondhur hilatnya denikang hestanika mulur adoh, durahitannya tan tuhu manungkul i jalu sasiki"

Artinya:

Bersama-sama memperbaiki hubungan dengan menjaga kesucian mulut wanita, jika bibir wanita tebal atas bawah hingga menutup gigi, serta lidahnya mundur karena bibirnya menjauh maju,pertanda wantia tersebut buruk rupa sehingga tidak mempesona bagi pria manapun" (Kakawin Smara Tantra, Wirama XIX.4).

Beberapa kutipan teks tersebut menjelaskan pengawi memberikan perhatian khusus pada penampilah fisik, tubuh, rambut, gigi, lidah dan bibir wanita. Mitos kecantikan yang ideal di kontruksi oleh pengawi untuk mengintimidasi wanita dan pembaca dengan cara sistematis melalui teks kakawin tersebut. Wanita akan merasa terdiskriminasi sebagai akibat penampilan fisik atau tubuhnya yang tidak ideal, sebagaimana disampaikan oleh kakawin Smara Tantra. Selama ajaran dalam kakawin Smara Tantra itu terwarisi dari generasi ke generasi maka selama itu wanita akan berpikir bahwa menjadi cantik sesuai dengan representasi kacamata masyarakat adalah satu kebutuhan yang mutlak, mitos kecantikan akan selalu membelenggu. Lebih mendalam pengarang menunjukkan kuasa hegemoninya dengan membandingkan wanita yang ideal dan wanita yang tidak ideal sesuai kharakteristiknya. Adapun isi teksnya adalah sebagai berikut.

"Stri yan teki magöng parambutanika Iwir duk sawangnya sugal, yan teki mapanjang addhuta magöng rakwa mangun dur gati, menggal randa ajarnya len tiki hangng stri kottama jar nika, romanya dawa tar magong tar adhemit Iwir megha mekel katon"

Artinya:

Ada juga wanita yang rambutnya lebat bagaikan sapu duk terlihat kasar dan kaku, meskipun panjangnya terlihat bagus dan debat tetapi sifatnya buruk, sehingga ia akan cepat menjanda, berbeda dengan wanita yang pandai menjaga kelakuannya, rambut wanita yang demikian itu panjang, tidak lebat dan tidak jarang bagaikan awan yang bergulung" (Kakawin Smara Tantra, Wirama XVII.5).

Pengawi "pengarang" dengan jelas melakukan perbandingan fisik terhadap wanita, hal ini terkesan memunculkan body shaming. Wanita yang ideal bagi pengawi adalah wanita berambut panjang, tidak lebat bagaikan awan bergulung, sedangkan wanita yang tidak ideal adalah wanita yang rambutnya lebat bagaikan sapu ijuk (duk) terlihat kasar, kaku dan panjang maka wanita itu sifatnya buruk dan divonis oleh pengawi akan cepat menjanda atau ditinggal pasangannya. Tentunya apa yang disampaikan oleh pengawi dalam kakawin Smara Tantra belum bisa dinyatakan kebenarannya tetapi lebih mengarah dan mengindikasikan diskrimasi bagi wanita yang memiliki ciri-ciri tersebut, terlebih lagi jika wanita tersebut membaca teks kakawin Smara Tantra. Selain menimbulkan perasaan kurang nyaman bagi kaum wanita, teks kakawin Smara Tantra juga telah mengkonstruksi kaum wanita ketika membaca teks tersebut. Mitos-mitos kecantikan yang diciptakan dalam kakawin Smara Tantra telah membelenggu kaum wanita sehingga menjadikan kaum wanita 
tidak lagi menghormati dirinya sendiri dan hanya terfokus pada bentuk fisik semata. Meskipun sejatinya kecantikan kaum wanita tidak hanya terpancarkan dari fisik tetapi haruslah diimbangi dengan kecantikan yang bersumber dari dalam (inner beauty).

\section{PENUTUP}

\section{Simpulan}

Teks kakawin Smara Tantra menyatakan kecantikan merupakan bagian dari kodrat yang harus disandang oleh kaum wanita. Realitas tersebut menyiratkan tentang suatu hal bahwa kecantikan adalah bagian integral dari diri wanita. Mitos kecantikan yang dimuat telah mengintimidasi kaum wanita tentang kecantikan menjadi suatu kebutuhan yang mutlak dan hanya diperuntukkan bagi kaum patriarki saja. Kaum wanita diibaratkan dan diharuskan untuk menciptakan stereotip baik dan layak untuk dimiliki dan diminati oleh kaum laki-laki. Pengontrolan tubuh seperti yang dijelaskan pada teori mitos kecantikan Naomi Wolf telah mengarah pada konteks seksualitas dari segi patriarki. Sebab pada kakawin Smara Tantra yang cukup terkenal pada kalangan masyarakat Bali hanya melihat dari sudut pandangan kaum laki-laki atas konstruksi cantik wanita. Mitos-mitos kecantikan yang diciptakan dalam kakawin Smara Tantra telah membelenggu kaum wanita sehingga menjadikan kaum wanita tidak lagi menghormati dirinya sendiri dan hanya terfokus pada bentuk fisik semata. Meskipun sejatinya kecantikan kaum wanita tidak hanya terpancarkan dari fisik tetapi haruslah diimbangi dengan kecantikan yang bersumber dari dalam (inner beauty).

\section{DAFTAR PUSTAKA}

Barthes, Roland. (2013). Mitologi.

Yogyakarta: Kreasi Wacana Suryoputri.

Bungin, Burhan. 2001.Metodologi Penelitian

Sosial. Surabaya: Universitas Airlangga.

Moleong, Lexy J. 1990. Metodologi

Penelitian Kualitatif. Bandung: Remaja

Rosdakarya

Perry, dan Potter. (2005). Buku Ajar

Fundamental Keperawatan. Jakarta:

EGC.

Pichard, Michel. 2006. Bali: Pariwisata

Budaya dan Budaya Pariwisata. Jakarta:

Perpustakaan Populer Gramedia.

Sudaryanto. 2015. Metode dan Aneka Teknik

Analisis Bahasa: Pengantar Penelitian

Wahana Kebudayaan secara Linguistik.

Yogyakarta: Sanata Dharma University Press.

Sugihastuti dan Suharto. 2002. Kritik Sastra

Feminis: Teori Dan Aplikasinya. Yogyakarta; Pustaka Belajar.

Susilo, D., \& Kodir, A. (2016). Politik tubuh

perempuan: bumi, kuasa, dan perlawanan. Jurnal Politik, 1(2), 317330

Wiyatmi. (2012). Kritik Sastra Feminis. Yogyakarta: Penerbit Ombak.

Wolf, Naomi. (2004). Mitos Kecantikan: Kala Kecantikan Menindas Perempuan. Yogyakarta: Niagara.

Zoetmulder, PJ. (1985). Kalangwan Sastra Jawa Kuna Selayang Pandang. Jakarta: Djambatan.

Zoetmulder, PJ. (2004). Kamus Jawa KunaIndonesia. Jakarta: Gramedia Pustaka Utama.

Lontar: No. 355. Kode III C. Kakawin Smara Tantra. No. Lontar 1097. No Keropak 13. Halaman 6. (Katalogus Lontar 2018 dalam informasi web Bulelengkab.go.id atau pada museum Gedong Kirtya). 